\title{
De la práctica clínica a la publicación científica: errores del lenguaje en la redacción médica
}

\author{
From clinical practice to scientific publication: language errors in medical writing
}

\section{Señor Editor:}

El lenguaje escrito es el medio más usado para la comunicación de los hallazgos obtenidos en la investigación científica; por lo tanto, el conocimiento de las normas del uso correcto del lenguaje en que se publica, es una competencia mínima e inherente al investigador y al comité editorial de cada revista (1).

La gran cantidad de errores lingüísticos en las publicaciones médicas en español constituye un problema actual que merece atención. Pese a la existencia de numerosos manuales de redacción científica, es muy difícil encontrar un artículo científico con menos de dos errores de este tipo (2), lo cual puede convertir un artículo metodológicamente impecable en un escrito confuso, ininteligible e impublicable.

Se revisaron dieciséis artículos originales, elegidos al azar, publicados en el último número disponible de cada una de las ocho revistas médicas peruanas indizadas en SciELO. Con sorpresa, se hallaron tales deficiencias en la redacción de todos los artículos revisados.

Se encontraron errores ortográficos, como los de acentuación gráfica (p. ej. "métodología" por "metodología", "clinico" en lugar de "clínico", etc.), los de puntuación y aquellos por uso excesivo de mayúsculas (p. ej. "APGAR", "CERO", "Gram Positivas", etc.); errores tipográficos (p. ej. "ue" en lugar de "que", "muestro" por "muestreo", etc.); errores gramaticales, como el abuso del gerundio (p. ej. “...basándose en el libro de nacimientos y completándose los datos con sus historias clínicas, utilizándose una ficha...”), uso incorrecto de la voz pasiva y numerosos defectos sintácticos, así como errores léxicos y otros vicios del lenguaje, sobre todo, anglicismos (p. ej. "data", "primers", "carriers"). Es evidente, por tanto, que los errores lingüísticos son un problema frecuente en las publicaciones médicas peruanas.

Todo investigador tiene el deber de evitar al máximo los errores en la redacción de sus artículos científicos. Muchas veces, se considera que la gramática es un aspecto secundario a la publicación, a pesar que el informe de toda investigación siempre consiste en un texto (3).

En los últimos años, la producción científica ha aumentado en nuestro país y, con frecuencia, los editores están sobresaturados con manuscritos por revisar. Sin embargo, bajo ninguna circunstancia, esto implica justificación para no corregir los errores lingüísticos, y menos aquellos de fácil corrección, como los errores de acentuación o duplicación de letras, que restan rigor científico a la publicación y ponen en riesgo la calidad de la revista donde se publican estos artículos $(2,4)$.

En la práctica clínica, es común el uso de tecnicismos y extranjerismos, como second look, rash, stent, etc., los cuales tienen términos equivalentes en español; pero, por su uso frecuente, se han convertido en una tendencia que amenaza la buena redacción médica.

Finalmente, las deficiencias del uso idiomático constituyen un problema con responsabilidad compartida por los investigadores y editores. Se han propuesto diversas soluciones, como la corrección del manuscrito previa a su envío o la revisión porcorrectores de estilo. Sin embargo, creemos que la medida más eficiente en busca de la excelencia de 
nuestras publicaciones es concienciar de la magnitud del problema a todos los investigadores de las ciencias médicas para su eficaz y oportuna solución.

\section{Wilder Leonardo Olivera ${ }^{1, a}$, María Villalobos Aguinaga $^{1, a}$, Jorge Fernández Mogollón ${ }^{1, b ; 2, c}$}

\section{Correspondencia:}

Wilder Alexander Leonardo Olivera

Pje. Ortiz Vélez 128, Chiclayo - Perú.

Correo electrónico: walo.9.128@gmail.com

\section{REFERENCIAS BIBLIOGRAFICAS}

1. González A. Defectos gramaticales y de estructuración literaria más frecuentes. Uso de términos incorrectos. Rehabilitación (Madrid). 2001;35(3):131-134.
2. Rodríguez L, Cuéllar A, Molina A. La calidad en la edición de textos: un reto para las editoriales médicas cubanas. Acimed. (Internet) 2009 (Citado el 4 de diciembre del 2014); 19(4). Disponible en: http://scielo.sld.cu/scielo.php?pid=S1024-9435 2009000400007\&script=sci_arttext

3. Iscla A, Benavent A. Problemas del lenguaje médico actual. (III) Gramática y estilo. Papeles Médicos. 2002;11(1):18-23.

4. Cárdenas M. Los dislates en los escritos médicos. Arch Cardiol Mex 2010; 80(4):315-317.

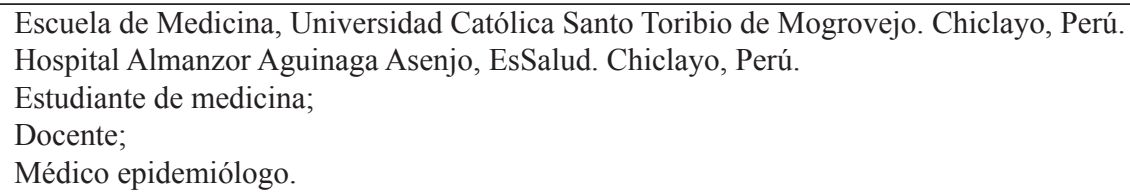

\section{Comentarios de los editores / Comments from editors}

Solo dos comentarios. En primer lugar, el artículo publicado en una revista científica es responsabilidad de los investigadores y de los editores; hay errores tipográficos, ortográficos y gramaticales que se podrían evitar si se toma con seriedad la revisión y aprobación de la prueba de impresión por los autores, que es la última etapa del proceso editorial.

En segundo lugar, recordar que la comunicación científica es de doble sentido, es decir el artículo de investigación lo debe entender el investigador y también el lector, en consecuencia a veces es necesario utilizar términos en inglés, para que el lector entienda el mensaje. Por ejemplo, los investigadores que trabajan en biología molecular utilizan y entienden mejor el término primers que cebadores que sería la traducción al castellano o el término carriers que transportistas o transportadores. Otro ejemplo son los nombres científicos para referirse a las especies de animales, plantas y especialmente microrganismos. 